\title{
PESQUISA EM MARKETING E ESTRATÉGIA NOS PRINCIPAIS PERIÓDICOS INTERNACIONAIS: UM ESTUDO BIBLIOMÉTRICO SOBRE PUBLICAÇÕES NO SÉCULO XXI
}

\section{RESUMO}

O relacionamento entre Marketing e Estratégia é investigado nesta pesquisa bibliométrica em vinte publicações dos principais periódicos acadêmicos, divididos igualmente quanto à área de conhecimento. Foram usadas técnicas de citação, cocitação, análise fatorial exploratória (AFE) e escalonamento multidimensional (EMD) para identificação dos trabalhos mais influentes, das abordagens conceituais empregadas e da evolução deste diálogo ao longo destes primeiros 14 anos do século XXI. A amostra selecionada foi composta por 5.270 artigos e mais de 130.000 citações, que tiveram forte influência conceitual da Visão Baseada em Recursos (VBR), Estratégia Baseada em Conhecimento, de trabalhos envolvendo Teoria dos Custos de Transação (TCT) e estratégia competitiva da Organização Industrial (OI). As referências mais citadas foram agrupadas em três fatores representando estas abordagens conceituais empregadas. Os resultados evidenciam: a) um crescimento representativo dos artigos utilizando as duas áreas nos periódicos de Marketing; b) VBR, TCT e OI como os temas de Estratégia mais utilizados para a abordagem de Marketing e; c) os estudos mais relevantes no período analisado. Este artigo propõe uma agenda para pesquisas futuras que aprofunde a investigação da relação entre Marketing e Estratégia e supra as lacunas apontadas.

Palavras-chave: Marketing; Estratégia; Estudo Bibliométrico; Análise de Cocitação; Análise Fatorial.

\section{SEARCH FOR MARKETING AND STRATEGY IN KEY INTERNATIONAL JOURNAL: A BIBLIOMETRIC PUBLICATIONS STUDY ON THE XXI CENTURY}

\begin{abstract}
This bibliometric study investigates Marketing and Strategy association in twenty relevant academic journals, divided equally between both fields. The methods used to identify the most influential studies; the most common conceptual approach and how researches from both areas evolved in the first fourteen years of the $21^{\text {st }}$ century were citation and cocitation network analysis, exploratory factor analysis (EFA) and metric multidimensional scaling (MDS). Sample size was comprised of 5,270 articles, embodying over 130,000 citations, which had a relevant conceptual influence on the Resource Based View (RBV), Knowledge Based View (KBV), Transaction Cost Theory (TCT) and competitive strategy of the Industrial Organization (IO). Uppermost cited references were clustered in three factors, representing the theoretical approach used when both disciplines are compiled. The results showed: a) meaningful increase on the number of papers encompassing both areas in Marketing journals; b) RBV, TCT and IO as the most used Strategic themes to connect with Marketing and c) the overall most cited studies in the period of analysis. Guidelines for future research are provided for further investigation on the combination of Marketing and Strategy, identifying possible gaps to be covered.
\end{abstract}

Keywords: Marketing; Strategy; Bibliometric Study; Co-Citation Analysis; Factor Analysis. 


\section{INVESTIGACIÓN DE MARKETING Y ESTRATEGIA EN CLAVE REVISTA INTERNACIONAL: UM ESTUDIO BIBLIOMÉTRICO SOBRE PUBLICACIONES EL SIGLO XXI}

\section{RESUMEN}

La relación entre el Marketing y Estrategia se investiga en este bibliométricos publicaciones de investigación en veinte de las principales revistas académicas, también dividida en el área de especialización. Se utilizaron técnicas de cotización, cocitação, análisis exploratorio de los factores (EPT) y el escalamiento multidimensional (EMD) para la identificación de las obras más influyentes de enfoques conceptuales utilizadas y la evolución de este largo de estos primeros 14 años del vigésimo primer diálogo siglo. La muestra seleccionada constaba de 5.270 artículos y más de 130.000 citas, que tuvieron gran influencia conceptual de el recurso basado Vista (RBV), Estrategia basada en el conocimiento, el trabajo que implica la Teoría de los Costes de transacción (TCT) y la estrategia competitiva de Organización Industrial (HOLA). Las referencias más citadas fueron agrupados en tres factores que explican estos enfoques conceptuales utilizados. Los resultados muestran: a) un crecimiento representante de artículos usando las dos áreas en revistas de comercialización; b) VBR, TCT y HI como las cuestiones de estrategia más utilizados para tratar y marketing; c) los estudios más importantes en el período analizado. En este artículo se propone una agenda para futuras investigaciones para profundizar en la investigación de la relación entre el Marketing y Estrategia y por encima de las lagunas identificadas.

Palabras clave: Marketing; Estrategia; Estudio Bibliométrico; Análisis Cocitação; Análisis de Factores.

Luiz Antonio de Camargo Guerrazzi ${ }^{1}$

Marcelo Moll Brandão ${ }^{2}$

Henrique de Campos Junior ${ }^{3}$

Carlos Eduardo Lourenço ${ }^{4}$

\footnotetext{
1 Mestrando em Administração na Universidade Nove de Julho - UNINOVE. Brasil. E-mail: luizguerrazzi@hotmail.com

${ }^{2}$ Doutor em administração pela Escola de Admnistração de Empresas de São Pauloda Fundação Getúlio Vargas EAESP/FGV. Professor do Programa de Pós Graduação em Administração da Universidade Nove de Julho PPGA/UNINOVE. Brasil. E-mail: marcelo.brandao@uninove.br

3 Doutor em administração pela Escola de Admnistração de Empresas de São Pauloda Fundação Getúlio Vargas EAESP/FGV. Professor da Escola de Admnistração de Empresas de São Pauloda Fundação Getúlio Vargas EAESP/FGV. Brasil. E-mail: henrique.junior@fecap.br

${ }^{4}$ Doutorando em administração pela Escola de Admnistração de Empresas de São Pauloda Fundação Getúlio Vargas EAESP/FGV. Professor da Escola de Admnistração de Empresas de São Pauloda Fundação Getúlio Vargas EAESP/FGV. Brasil. E-mail: caerib@gmail.com
} 


\section{INTRODUÇÃO}

O entrelaçamento entre marketing e estratégia remonta de longa data uma vez que Porter (1980) já sugere que a estratégia de marketing deve estar alinhada com o planejamento estratégico da empresa para que as vantagens competitivas alavanquem o seu desempenho. Kumar (2015) em estudo bibliográfico caracterizou os estudos da área de marketing por período de tempo e tema de interesse. Com base nessa categorização pode-se concluir que a partir de 2005 os artigos publicados no Jornal of Marketing (JM) apresentaram predominância de interesse em investimento de marketing como parte integrada da organização, vinculada ao posicionamento estratégico. Esses estudos se traduzem em pesquisas que buscam entender os investimentos em atividades de marketing direcionadas para os consumidores, a eficiência e efetividade dessas atividades no desempenho, e o valor da firma gerado pelo engajamento dos stakeholders e consumidores.

Vários são os autores e estudos que reforçam o alto grau de entrelaçamento entre marketing e estratégia, seja na produção acadêmica, ou na gestão das organizações. Dentre esses estudos as pesquisas apontam para: oportunidades de evolução teórica da área de estratégia com utilização de modelos de marketing (Barney, 2013); governança de distribuição em marketing apoiada pela teoria dos custos de transação (Williamson, 2010); relações entre formulação da estratégia de marketing e desempenho da organização (Dickson, Farris, \& Verbeke, 2001; Jaakkola, Moller, Parvinen, Evanschitzky, \& Muhlbacher, 2010; Theodosiou, Kehagias, \& Katsikea, 2012; Varadarajan \& Jayachandran, 1999). Teorias de estratégia são utilizadas em pesquisas de marketing de forma crescente, mas a visão baseada em recursos (VBR), abordagem teórica dominante a partir do final do século $\mathrm{XX}$, tem sido a mais utilizada na última década. Por exemplo, no trabalho de Kozlenkova, Samaha e Palmatier (2014) os autores constataram a publicação de 173 artigos voltados a marketing empregando VBR, entre 1990 e 2012.

Outro tema recorrente em trabalhos de marketing, também relacionado à VBR, diz respeito às capacidades dinâmicas. Teece, Pisano e Shuen (1997) salientam a necessidade de alinhar as capacidades da empresa com os esforços de marketing. Day (1994) relacionou as capacidades dinâmicas como recursos a serem empregados por empresas dirigidas ao mercado. Krasnikov e Jayachandran (2008) e Morgan, Vorhies e Mason (2009) também têm trabalhos sobre capacidades desenvolvidas na empresa com orientação ao mercado e desempenho. Sheng, Zhou, e Li (2011) e Simonin (1999), por sua vez, pesquisaram a relação entre alianças estratégicas e postura de marketing das empresas.
Alguns artigos publicados no $J M$ podem ser destacados como estudos chave na integração do marketing com os processos organizacionais e criação de valor para shareholders (Srivastava, Shervani, \& Fahey, 1999), com a análise de valor da governança para as decisões estratégicas de marketing (Ghosh \& John, 1999), com a estratégia da empresa (Frels, Shervani, \& Srivastava, 2003; Johnson, Sohi, \& Grewal, 2004). Outros exemplos da relação entre marketing e estratégia podem ser exemplificados por edições especiais em periódicos relevantes na área de marketing para a aplicação da TCT em marketing no Journal of Retailing (vol. 86, n.. 3, 2010) com um artigo de Oliver Williamson reconhecendo a integração entre as áreas, e edição especial do Journal of The Academic of Marketing Science (vol. 42, n. 1, 2014), no qual Jay B. Barney discute em um artigo as vantagens e possibilidades da evolução dos estudos da VBR em integração com a área de marketing. Este estudo bibliométrico investiga os principais temas estudados concomitantemente nas áreas de estratégia e marketing, em periódicos relevantes, e sugere uma possível agenda de pesquisa futura.

Neste artigo foram empregadas técnicas bibliométricas em trabalhos publicados em 20 periódicos internacionais, no período de 2001 a 2014, classificados pelo fator de impacto publicado no portal JCR Social Sciences Edition-2014. Foram selecionados 10 periódicos especializados em marketing e 10 em estratégia. Nesses periódicos foram coletados 5270 artigos no portal Web of Science da Thomson-Reuters. Os artigos da amostra foram submetidos às análises de frequência de citação e de cocitação. Uma análise fatorial exploratória também foi executada com o objetivo de identificar subcampos de uniformidade conceitual dentro da amostra (Lin \& Cheng, 2010).

$\mathrm{O}$ artigo está composto por quatro partes. $\mathrm{Na}$ primeira parte é feita uma revisão da teoria sobre VBR e TCT, principais abordagens teóricas utilizadas. Organização Industrial, por ser uma abordagem teórica em declínio a partir do final do século XX, não será abordada no referencial teórico. $\mathrm{Na}$ segunda parte é detalhado o método empregado, os procedimentos usados para a obtenção da amostra e as técnicas para sua análise. $\mathrm{Na}$ sequência são apresentados os resultados obtidos e na última parte são feitas as considerações finais, apontando limitações deste trabalho e direções para novas pesquisas.

\section{REVISÃO DA LITERATURA}

\subsection{A Visão Baseada em Recursos - VBR e Marketing}

A VBR tem sua origem no trabalho de Edith Penrose (1959) "The Theory of the Growth of the 
Firm" no qual afirma que uma empresa pode ser entendida como um conjunto de recursos produtivos. Recursos são definidos por ela como o que a empresa compra, aluga ou produz para seu uso e as pessoas contratadas que fazem parte do seu quadro de colaboradores; argumenta, ainda, que é a heterogeneidade desses recursos que proporciona às empresas seus aspectos idiossincráticos. $\mathrm{O}$ foco da VBR situa-se no interior da empresa, em explorar ou adquirir recursos que sejam vantagens competitivas, faz assim, uma contraposição à lógica da organização industrial, na qual a empresa deveria definir a conduta a partir da estrutura do mercado. Uma tradução dessa visão de estrutura de mercado foi sugerida e largamente adotada na área de estratégia por meio do modelo das 5 Forças de Porter (1980, 1985).

A primeira edição do volume 42 (2014) do Journal of the Academy of Marketing Science foi dedicado a aplicações da Visão Baseada em Recursos (VBR) devido à relevância desta teoria em trabalhos de marketing. Kozlenkova, Samaha e Palmatier (2014), no primeiro artigo da edição especial, chama a atenção para o crescimento de mais de $500 \%$ no uso da VBR em pesquisas de marketing em análises de vantagens competitivas e de resultados. Wernerfelt (2014) afirma que a VBR se relaciona com quase todos os aspectos estudados por marketing, com ênfase nas discussões sobre os 4P's (produto, preço, promoção e praça). Barney (2013) afirma que a proximidade entre marketing e VBR é uma relação que beneficia as duas teorias uma vez que abordagens próprias de atividades de marketing são úteis para aprofundar aspectos da VBR.A importância da VBR como uma nova opção à gestão estratégica foi decorrente dos artigos de Lippman e Rumelt (1982) sobre diferenças de desempenho explicadas pela imitabilidade imperfeita das condições de competição entre empresas, Wernerfelt (1984), Barney (1986) sobre o aproveitamento de recursos internos à empresa para caracterizar vantagens competitivas em face de outros competidores e Barney (1986), Dierickx e Cool (1989) e Penrose (1959) que caracterizaram as condições necessárias para que os recursos se constituam em vantagens competitivas sustentáveis, estas sim, pilares de uma posição estratégica responsável pela obtenção de bons desempenhos. Barney (1986) e Barney e Hesterly (2009) argumentam que um recurso deve ser valioso, raro, não substituível e de difícil imitação para que seja base de uma vantagem competitiva sustentável.

Barney, Ketchen e Wright (2011) afirmam que a VBR parece ter atingido a maturidade como uma teoria o que leva à necessidade de revitalização, caso contrário preveem seu declínio. Os autores citam cinco temas em que a VBR pode ainda ser ampliada para novas direções, são eles: inter-relacionamento com outras perspectivas, processos de aquisição e desenvolvimento de novos recursos, pesquisas voltadas aos fundamentos da VBR, pesquisas em sustentabilidade e questões sobre método e medição. O estreitamento nas associações entre VBR e marketing alinha-se com a revitalização necessária para a teoria. Os autores também argumentam que ao logo dos anos, o conceito de VBR se expandiu incorporando, por exemplo, variantes como visão baseada em conhecimento (Grant, 1996) capacidades dinâmicas (Teece, Pisano \& Shuen, 1997). A visão baseada no conhecimento é uma extensão da VBR ao definir que empresas também produzem conhecimento, que é heterogêneo entre empresas de um mesmo setor e que se constitui num recurso estratégico e sustentável (Kogut \& Zander, 1996; Zander \& Kogut, 1995). Cohen e Levinthal (1990) introduziram o conceito de capacidade absortiva para a capacidade de uma empresa em reconhecer o valor de informações novas, assimilá-las e aplicá-las para obtenção de desempenho superior.

O conceito de capacidades dinâmicas é um desdobramento da VBR da qual se diferencia por explorar não apenas aspectos internos da empresa como também os externos a ela (Teece et al., 1997). Os autores, no artigo considerado como introdutório deste novo paradigma (Eisenhardt \& Martin, 2000; Helfat \& Peteraf, 2009), definem capacidades dinâmicas como as habilidades da empresa em integrar, construir e reconfigurar recursos internos e externos para a obtenção de um novo posicionamento requerido pelas mudanças que ocorrem num ambiente dinâmico e competitivo. Teece (2007) afirma que capacidades dinâmicas permitem às empresas criar, implantar e proteger os ativos intangíveis que suportam o desempenho superior do negócio em longo prazo e que em ambientes de negócio dinâmicos e abertos à concorrência global, a vantagem competitiva sustentável requer capacidades dinâmicas raras e de difícil imitação. As capacidades dinâmicas podem ser desdobradas em capacidade de perceber e anular ameaças, em capturar oportunidades, e naquelas usadas para manter a competitividade por meio de reforçar, combinar, proteger, e, quando necessário, reconfigurar ativos tangíveis e intangíveis da empresa.

Contribuições da VBR em marketing são apontadas por Barney (2013). Argumenta que a frequência de utilização bem como a profundidade das análises sugere que as duas áreas mantém um diálogo produtivo. Pondera que não apenas a VBR pode ser aplicada para analisar questões de marketing, como também pode beneficiar-se do fato de pesquisas de marketing ajudarem a elucidar lacunas do estudo de VBR. Cita três campos onde isso é observado: no uso de modelos quantitativos para identificar e avaliar recursos, principalmente produtos, quanto ao potencial de geração de resultado; na introdução da dinâmica comportamental do mercado para a análise estratégica, ajudando a explicar o desempenho da empresa e na prospecção da formação da marca (recurso) e relacionamento com outras empresas.

O crescimento da colaboração de VBR e marketing foi verificado por Kozlenkova, Samaha e Palmatier (2014) que identificaram 173 artigos de 
marketing com aplicações diretas de VBR, publicados entre 1990 e 2012, apontando para um crescimento significativo nos últimos anos da amostra. Identifica quatro abordagens de uso da VBR: em aspectos internos de marketing (estratégia e inovações de marketing); na análise de recursos específicos de marketing (marca, relacionamentos); na verificação de vantagens críticas sustentáveis nas trocas de marketing e no uso conjunto com outras teorias relacionadas (custos de transação e custos de agência).Wernerfelt (2014) afirma que uma grande quantidade de trabalhos em marketing trata de capacidades, competição e competências, principalmente quando abordam os 4P's (produto, preço, promoção e praça) que, por si só, já se constituem em aspectos da VBR. Day (1994) complementa argumentando que numa empresa orientada para o mercado, as capacidades internas podem aproximar o planejamento estratégico à política de qualidade fortalecendo o foco do negócio. Capacidades e recursos inerentes às atividades de marketing conferem vantagens competitivas sustentáveis, pois são de difícil imitação e substituição por competidores devido ao conhecimento adquirido e inerente a essas capacidades (Krasnikov \& Jayachandran, 2008; Morgan, Vorhies \& Mason, 2009).

\subsection{Teoria dos Custos de Transação (TCT) e Marketing}

A terceira edição do volume 86 (2010) do Journal of Retailing foi dedicada à TCT e teve o artigo de abertura elaborado por Oliver Williamson. Esta edição especial teve como objetivo apontar as contribuições da TCT para o marketing. A TCT foi desenvolvida por Williamson $(1975,1985)$ a partir de artigo seminal The Nature of the Firm de Ronald Coase (1937) e tem como foco a identificação das razões que levam as empresas a optar pela produção própria ou pela terceirização. Custos de transação são os custos envolvidos nas transações que ocorrem na gestão das empresas e cuja análise objetiva sua minimização. Para Williamson $(1975,1985)$ toda transação envolve duas situações que levam à ocorrência destes custos: a primeira está associada ao comportamento dos indivíduos que, de acordo com a teoria, têm racionalidade limitada, que os leva a atitudes oportunistas e a segunda situação diz respeito à impossibilidade da solução que maximize a eficiência devido à falta de conhecimento total do ambiente. Os custos de transação são os gastos econômicos para gerir transações e garantir a execução dos termos contratuais.

Os artigos associando TCT e marketing tiveram crescimento relevante nas últimas três décadas (Williamson \& Ghani, 2012) gerando contribuições importantes para as duas áreas. Na revisão de Richman e Macher (2008), os autores afirmam que o marketing é o segundo campo mais explorado em artigos de TCT. Identificaram que os principais pontos abordados em artigos de marketing foram integração vertical da empresa, internacionalização, aquisições e fusões, gestão do canal de distribuição e gestão e remuneração da força de vendas. Estas abordagens podem ser vistas em John e Reve (2010); Steenkamp e Geyskens (2012;) Teece (2010) e Wu (2013).

\section{MÉTODO}

Esta pesquisa foi desenvolvida utilizando-se de um estudo bibliométrico, ferramenta estatística usada para mapear e gerar diferentes indicadores de tratamento e gestão da informação e do conhecimento produzido em determinada área (Guedes \& Borschiver, 2005).

O estudo bibliométrico permite mapear e gerar diferentes indicadores de tratamento e gestão da informação e do conhecimento minimizando a subjetividade inerente à recuperação das informações e traz o conhecimento produzido em determinada área (Guedes \& Borschiver, 2005). Este método mostra-se apropriado à proposta desse artigo, pois permitiu identificar as principais publicações, autores e abordagens ao longo dos anos, ilustrando os principais agrupamentos de conhecimentos e as relações gerais entre eles (Broadus, 1987; Pilkington \& Meredith, 2009). As principais ferramentas de análise de um estudo bibliométrico são as análises de citação e cocitação (Ramos-Rodríguez \& Ruíz-Navarro, 2004).

A análise de citações permite a identificação dos principais pesquisadores e obras que formam a estrutura intelectual do tema da pesquisa e é um importante indicador para os tópicos e teorias empregados nos trabalhos de marketing e estratégia, possibilitando uma análise mais rigorosa na quantificação da reputação, influência e prestígio do conhecimento por meio de sua produção acadêmica e da identificação dos periódicos onde são publicadas (Palacios-Huerta \& Volij, 2003). A cocitação ocorre quando dois artigos são citados em conjunto em um ou mais artigos, nessa análise é medido o grau de ligação entre esses dois ou mais artigos pelo número de documentos que os citam (Guedes \& Borschiver, 2005; Ramos-Rodríguez \& Ruíz-Navarro, 2004; Serra, Ferreira, \& Almeida, 2013; Shafique, 2013) revelando padrões de associação entre os autores.

Estudos bibliométricos têm sido utilizados para levantamento do conhecimento acadêmico. Assim, Brown e Dant (2008, 2009) estudaram aspectos conceituais e metodológicos empregados em trabalhos sobre o marketing de varejo; Hoffman e Holbrook (1993) investigaram a estrutura intelectual utilizada em pesquisas com consumidores e Chabowski, Samiee e Hult (2013) fizeram um estudo sobre a literatura relacionada a marcas globais. Em estratégia, RamosRodrigues e Ruíz-Navarro (2004) pesquisaram a produção acadêmica publicada por um único periódico (Strategic Management Journal); Acedo, Barroso e Galan (2006) estudaram trabalhos envolvendo aspectos 
da VBR e Nerur, Rasheed e Natarajan (2008) a estrutura intelectual da administração estratégica.

A Figura 1 traz o desenho da pesquisa e os procedimentos adotados para atender aos objetivos propostos. A pesquisa foi composta por uma análise de citações para medir a frequência com que as referências bibliográficas usadas na amostra são citadas, a seguir foi desenvolvida uma análise de cocitação, identificando os pares de artigos citados simultaneamente, seguido por uma análise fatorial exploratória para redução de fatores com o intuito de agrupar as referências e, na última etapa, foi elaborado mapa de cocitações com o emprego do escalonamento de proximidades multidimensional.

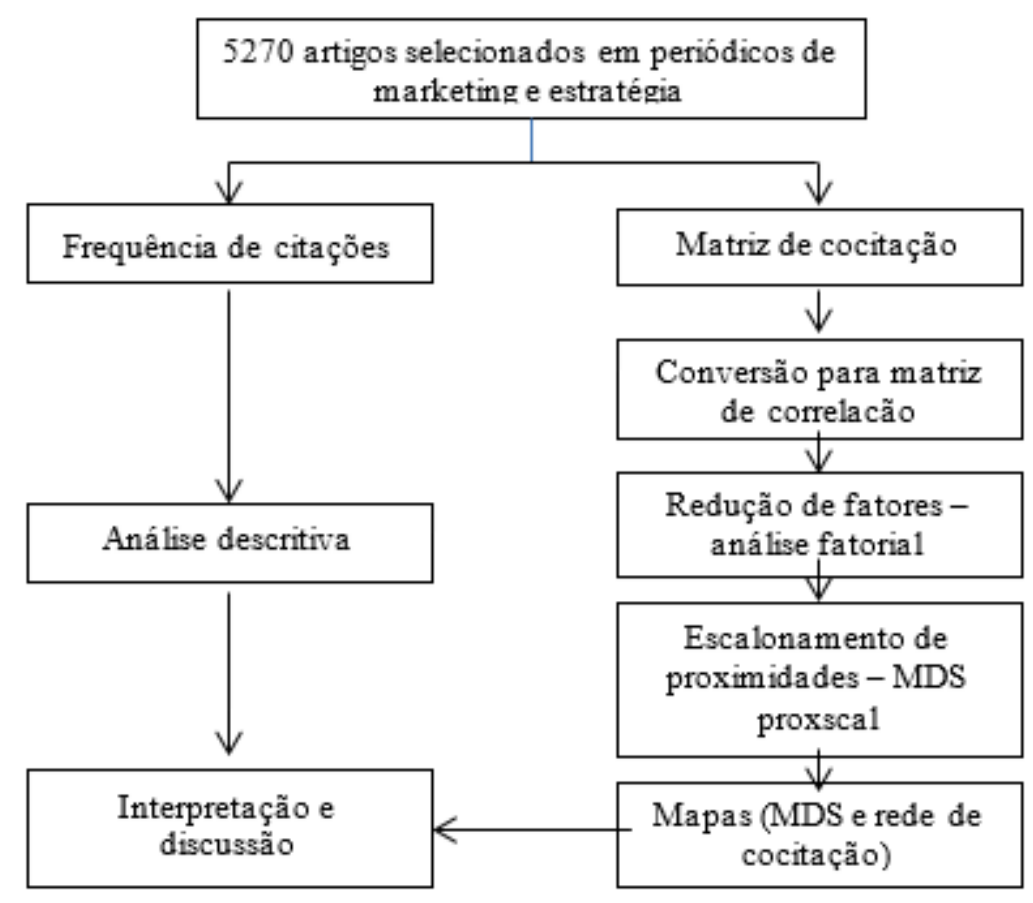

Figura 1 - Desenho da pesquisa

Fonte: Adaptado pelo autor de Ramos-Rodrigues e Ruiz-Navarro (2004)

\subsection{Procedimentos da Pesquisa}

Esta pesquisa se utiliza exclusivamente de artigos publicados em periódicos selecionados por sua relevância em temas relacionados a estratégia e marketing. Foram coletados na base de dados ISI Web of Knowledge da Thomson Reuters. Essa base possui ferramentas de busca que facilitam a pesquisa bibliométrica. Os dados foram coletados em dezembro de 2014 diretamente da plataforma Web of Knowledge (http://apps.webofknowledge.com).

Optou-se para a realização desta pesquisa pela utilização de múltiplos periódicos, pois jornais acadêmicos têm um importante papel na disseminação do conhecimento e no reconhecimento do mérito dos trabalhos devido a sua publicação (Palacios-Huerta \& Volij, 2003). A utilização de várias fontes têm a vantagem de uma cobertura mais ampla e evita potencial vieses causados pela linha editorial que um estudo baseado num único periódico poderia ter (Shafique, 2013).

Para seleção dos periódicos utilizados, optouse por aqueles com maior probabilidade de publicarem artigos em marketing e estratégia. Foram escolhidos os mais bem ranqueados por fator de impacto agregado de cinco anos, presentes no JCR Social Sciences Edition2014, nas categorias business, business/finance $e$ management. A análise foi confirmada com a Journal Quality List do portal Ann-Will Harzing. Foram selecionados 20 periódicos, 10 deles de estratégia e os restantes especializados em marketing, conforme Tabela 1. O intervalo de tempo pesquisado restringiuse a este século, aos artigos publicados e presentes no portal a partir de 2001 até dezembro de 2014. 
Pesquisa em Marketing e Estratégia nos Principais Periódicos Internacionais: Um Estudo Bibliométrico sobre Publicações no Século XXI

Tabela 1 - Seleção da amostra - Periódicos de estratégia

\begin{tabular}{|c|c|c|c|c|c|c|c|}
\hline $\begin{array}{l}\text { Área do } \\
\text { Periódico }\end{array}$ & Journal * & $\begin{array}{l}\text { Fator de } \\
\text { Impacto } \\
\text { 5Y - JCR }\end{array}$ & $\begin{array}{c}1^{\circ} \text { ano } \\
\text { disponível } \\
\text { no ISI }\end{array}$ & $\begin{array}{c}\text { Total de } \\
\text { artigos } \\
\text { no ISI }\end{array}$ & $\begin{array}{c}\text { Artigos } \\
\text { sobre } \\
\text { Estratégia/ } \\
\text { Marketing } \\
\end{array}$ & $\begin{array}{c}\text { \% por } \\
\text { periódico }\end{array}$ & $\begin{array}{c}\% \text { da } \\
\text { amostra }\end{array}$ \\
\hline \multirow{11}{*}{ Estratégia } & $\begin{array}{l}\text { Academy of Management } \\
\text { Annals }\end{array}$ & 10,154 & 2007 & 106 & 18 & 17 & 1.2 \\
\hline & $\begin{array}{l}\text { Academy of Management } \\
\text { Review }\end{array}$ & 9,698 & 1983 & 2071 & 64 & 3 & 4.4 \\
\hline & $\begin{array}{c}\text { Academy of Management } \\
\text { Journal }\end{array}$ & 8,443 & 1958 & 3176 & 157 & 5 & 10.7 \\
\hline & Journal of Management & 8,027 & 1983 & 1515 & 112 & 7 & 7.6 \\
\hline & $\begin{array}{c}\text { Administrative Science } \\
\text { Quarterly }\end{array}$ & 7,057 & 1956 & 3472 & 92 & 3 & 6.3 \\
\hline & $\begin{array}{l}\text { Strategic Management } \\
\text { Journal }\end{array}$ & 5,929 & 1980 & 2189 & 431 & 20 & 29.4 \\
\hline & Organization Science & 5,512 & 1990 & 1365 & 220 & 16 & 15.0 \\
\hline & $\begin{array}{c}\text { Journal of Management } \\
\text { Studies }\end{array}$ & 5,196 & 1966 & 2617 & 186 & 7 & 12.7 \\
\hline & Long Range Planning & 4,365 & 1968 & 4101 & 123 & 3 & 8.4 \\
\hline & $\begin{array}{l}\text { Academy of Management } \\
\text { Perspectives }\end{array}$ & 3,766 & 2006 & 401 & 63 & 16 & 4.3 \\
\hline & TOTAL ESTRATÉGIA & & & 21013 & 1466 & 7 & 100 \\
\hline \multirow{12}{*}{ Marketing } & Journal of Marketing & 6,682 & 1956 & 4407 & 277 & 6 & 7.3 \\
\hline & Journal of Business Research & 2.341 & 1973 & 4547 & 970 & 21 & 25.5 \\
\hline & $\begin{array}{c}\text { Journal of Marketing } \\
\text { Research }\end{array}$ & 3,796 & 1964 & 3670 & 204 & 6 & 5.4 \\
\hline & $\begin{array}{c}\text { Industrial Marketing } \\
\text { Management }\end{array}$ & 2,366 & 1971 & 2649 & 747 & 28 & 19.6 \\
\hline & $\begin{array}{l}\text { Journal of the Academy of } \\
\text { Marketing Sciences }\end{array}$ & 4,518 & 1997 & 886 & 235 & 27 & 6.2 \\
\hline & $\begin{array}{c}\text { Journal of Product } \\
\text { Innovation Management }\end{array}$ & 2,770 & 1984 & 1751 & 426 & 24 & 11.2 \\
\hline & Marketing Science & 3,012 & 1987 & 1216 & 328 & 27 & 8.6 \\
\hline & $\begin{array}{c}\text { European Journal of } \\
\text { Marketing }\end{array}$ & 1,569 & 1971 & 1461 & 384 & 26 & 10.1 \\
\hline & Journal of Retailing & 2,452 & 1956 & 2219 & 143 & 6 & 3.8 \\
\hline & $\begin{array}{c}\text { Journal of Service Research } \\
\text { - US } \\
\end{array}$ & 4,109 & 2004 & 301 & 90 & 30 & 2.4 \\
\hline & TOTAL MARKETING & & & 23107 & 3804 & 16 & 100.0 \\
\hline & TOTAL GERAL & & & 44120 & 5270 & & $12 \%$ \\
\hline
\end{tabular}

Fonte: Dados coletados do ISI.

Elaborada pelos autores.

Definidos os periódicos e o período da pesquisa, conduziu-se a busca por palavras-chave na opção "topic", sendo inserida uma palavra-chave por vez para cada periódico consultado. As palavras-chave foram: strat* (o asterisco permite a busca para qualquer derivação do radical), marketing (metrics, finance, stock return, mix, orientation), branding, RBV, TCT e capability* para condução da pesquisa nos periódicos de marketing e market* (mix, orientation) e branding para os periódicos de estratégia. Dessa forma foi possível levantarmos todos os artigos publicados nos periódicos selecionados para a pesquisa e que continham essas palavras seja no título, resumo ou palavras-chave.

A Tabela 1 apresenta como a amostra da pesquisa está distribuída em torno dos periódicos, nela observamos que o Strategic Management Journal foi, dentre os periódicos de estratégia, o que mais publicou 
artigos relacionados a marketing $(29,4 \%)$ e, dentre os periódicos de marketing, o Journal of Business Research foi o que mais publicou artigos de estratégia, 25,5\%. Constam do ISI 44.120 artigos, dos quais 5.270 foram relacionados para esta pesquisa, ou seja, $12 \%$.

\subsection{Amostra da pesquisa e espaço de publicação de} questões na fronteira entre Estratégia e Marketing

A análise longitudinal da amostra dos 5.270 artigos (1466 nos periódicos de estratégia e 3840 nos de marketing) mostrou que a produção científica sofreu variações ao longo dos anos (Figura 2). RamosRodríguez e Ruíz-Navarro (2004) e Serra, Ferreira e Almeida (2012) destacam que a motivação pelo tema de estratégia pode variar em decorrências de fatores econômicos da sociedade. A publicação de artigos sobre estratégia em periódicos de marketing cresceu de forma consistente nesta primeira década e meia deste século, no entanto mantendo-se estável a publicação de artigos relacionados a marketing em periódicos voltados à estratégia. Isto corrobora a constatação de que teorias de estratégia são usadas de forma crescente em pesquisas de marketing (Kozlenkova et al., 2014).

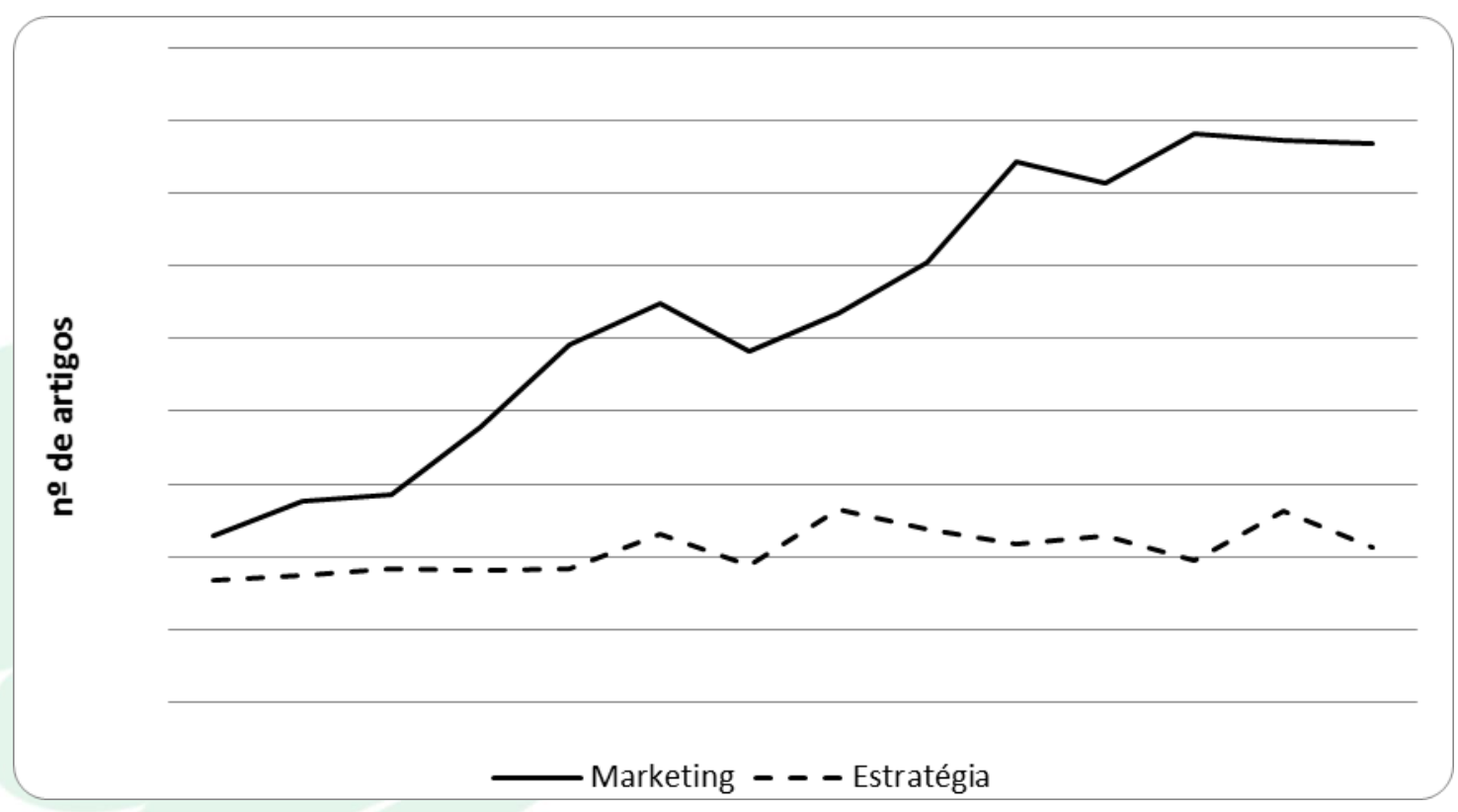

Figura 2 - Evolução de publicações em periódicos de estratégia e marketing Fonte: Elaborada pelos autores.

A diferença de tendência apresentada na Figura 2 suscita alguns questionamentos sobre o que poderia explicar o não crescimento de artigos que relacionem marketing e estratégia em periódicos da área de estratégia. Essa discussão fica mais interessante na medida em que parte dos artigos que relacionam as duas áreas publicados nos periódicos de marketing tem como autores referências da área de estratégia, ou seja, de 2101 autores listados, 336 deles (16\%) publicaram em periódicos das duas áreas. Em análise das referências teóricas dos artigos publicados por esses autores multiárea verificou-se que a teoria utilizada foi a RBV. Dessa forma, pode ser sugerido que investigações relevantes para a evolução das teorias na área de estratégia vêm tendo mais espaço em área correlata que na própria área.

\subsection{Procedimentos de Análise}

Neste estudo procedeu-se às análises de citação, cocitação e fatorial exploratória apoiada pelo escalonamento multidimensional (MDS) para todo o período da amostra. Para a análise bibliométrica foi utilizado o software Bibexcel (Pilkington, 2006), que permitiu a extração de informações quantitativas acerca da amostra da pesquisa. Por meio da utilização desse software foi criada a tabela de frequência de citação e a matriz de cocitações necessária para a criação do mapa de proximidades (MDS proxscal) cujo objetivo é analisar a proximidade dos dados e exprimi-la em distâncias euclidianas num diagrama bidimensional (Hair, Tatham, \& Black, 1995). Para rodar o MDS foi utilizado o software SPSS, versão 20 e o diagrama do resultado é apresentado na Figura 3.

Essas análises foram complementadas pela análise fatorial feita no SPSS e pela rede de cocitações elaborada pelo software Ucinet, versão 6 (Borgatti, Everett, \& Freeman, 2002). Para realizar essas análises, foi necessária a padronização das referências utilizadas visto que algumas das referências apresentavam inconsistências quanto ao nome dos autores (abreviaturas e sobrenomes), volumes, número, páginas e nomes dos periódicos. 
Foram consideradas para a elaboração da tabela de frequência de citações todas as referências dos 5270 artigos da amostra que foram classificadas, ordenadas e contadas. Esta pesquisa foi desenvolvida nos 49 artigos mais citados (acima de 120 vezes). Tabela 3 apresenta os trabalhos mais influentes para os períodos parciais considerados e para o período total.O segundo procedimento foi a análise de cocitação cujo objetivo foi de identificar os principais tópicos e teorias sobre o tema e de como se inter-relacionam (Lin \& Cheng, 2010; McCain, 1986; Ramos-Rodríguez \& Ruíz-Navarro, 2004). Esta análise baseia-se na matriz de cocitação, uma forma particular de matriz de proximidades (Bazeley, 2013). A análise pela matriz de proximidades é usada em pesquisas qualitativas, onde os códigos (artigos, neste caso) são colocados em linhas e colunas (Bernard \& Ryan, 2010). A matriz é a base para proceder-se à análise multivariada (Bazeley, 2013). Para a elaboração dessa matriz foram considerados igualmente os 49 artigos que receberam o maior número de citações.

A análise fatorial foi o terceiro procedimento de análise da amostra. Foi utilizado o método da rotação varimax (Acedo, Barroso, \& Galan, 2006; Lin \& Cheng, 2010) e análise multidimensional (MDS) realizada no SPSS. Foi utilizada a rotação varimax, pois seus resultados são mais facilmente interpretáveis porque forçam os vetores de resultado, representados pelos fatores para a menor correlação entre eles (Fabrigar, Wegener, \& MacCallun, 1999). A análise fatorial agrupa os artigos com base em sua proximidade temática ou conceitual num mesmo fator.
Foram considerados apenas valores maiores de 0.4 como pré-requisito para a variável pertencer a um fator (Lin \& Cheng, 2010; Nerur et al., 2008; Shafique, 2013). Cada fator representa um subtema de pesquisa do tema principal da pesquisa e é obtido pela matriz de proximidades. A análise MDS complementa e confirma a fatorial e permite uma imagem visual da força de ligação entre os artigos, ou seja, a frequência com que são cocitados (Bazeley, 2013).

\section{RESULTADOS}

Nesta seção, são apresentados os resultados da análise de citação e cocitações de autores e a análise fatorial realizado pelo levantamento das referências utilizadas na amostra dos 5270 artigos sobre marketing e estratégia publicados nos principais periódicos internacionais de administração.

\subsection{Análise de citações}

Os 5270 artigos da amostra utilizaram cerca de 130 mil referências. A Tabela 2 apresenta, dentre as referências, as mais citadas em períodos de cinco anos e para o período total da pesquisa. As colunas trazem a frequência de citações para os trabalhos publicados no período e a frequência relativa, indicando sua relevância para o período. Desta forma, Barney (1991), com 713 citações, foi o mais citado em toda a amostra e também nos três períodos.

Tabela 2 - Frequência de citação por período e total

\begin{tabular}{|c|c|c|c|c|c|c|c|c|}
\hline & \multirow{2}{*}{\multicolumn{2}{|c|}{$\begin{array}{c}2001-2005 \\
n=1277\end{array}$}} & \multirow{2}{*}{\multicolumn{2}{|c|}{$\begin{array}{c}2006-2010 \\
n=2026\end{array}$}} & \multirow{2}{*}{\multicolumn{2}{|c|}{$\begin{array}{c}2011-2014 \\
n=1967\end{array}$}} & \multirow{2}{*}{\multicolumn{2}{|c|}{$\begin{array}{c}2001-2014 \\
n=5270\end{array}$}} \\
\hline & & & & & & & & \\
\hline & $n$ & $\%$ & $n$ & $\%$ & $n$ & $\%$ & $n$ & $\%$ \\
\hline Barney (1991) & 180 & 14.1 & 270 & 13.3 & 263 & 13.4 & 713 & 13.5 \\
\hline Teece, Pisano e Shuen (1997) & 91 & 7.1 & 174 & 8.6 & 175 & 8.9 & 440 & 8.3 \\
\hline Day (1994) & 118 & 9.2 & 174 & 8.6 & 142 & 7.2 & 434 & 8.2 \\
\hline Porter (1980) & 145 & 11.4 & 155 & 7.7 & 121 & 6.2 & 421 & 8.0 \\
\hline Wernerfelt (1984) & 116 & 9.1 & 150 & 7.4 & 126 & 6.4 & 392 & 7.4 \\
\hline Cohen e Levinthal (1990) & 83 & 6.5 & 149 & 7.4 & 145 & 7.4 & 377 & 7.2 \\
\hline Williamson (1985) & 103 & 8.1 & 136 & 6.7 & 105 & 5.3 & 344 & 6.5 \\
\hline Porter (1985) & 103 & 8.1 & 115 & 5.7 & 110 & 5.6 & 328 & 6.2 \\
\hline Nelson e Winter (1982) & 98 & 7.7 & 122 & 6.0 & 106 & 5.4 & 326 & 6.2 \\
\hline March (1991) & 67 & 5.2 & 132 & 6.5 & 123 & 6.3 & 322 & 6.1 \\
\hline Pfeffer e Salancick (1978) & 105 & 8.2 & 114 & 5.6 & 92 & 4.7 & 311 & 5.9 \\
\hline Penrose (1959) & 88 & 6.9 & 105 & 5.2 & 111 & 5.6 & 304 & 5.8 \\
\hline Cyert e March (1963) & 69 & 5.4 & 117 & 5.8 & 99 & 5.0 & 285 & 5.4 \\
\hline Dyer e Singh (1998) & 57 & 4.5 & 111 & 5.5 & 114 & 5.8 & 282 & 5.4 \\
\hline
\end{tabular}


Pesquisa em Marketing e Estratégia nos Principais Periódicos Internacionais: Um Estudo Bibliométrico sobre Publicações no Século XXI

\begin{tabular}{|c|c|c|c|c|c|c|c|c|}
\hline Dimaggio (1983) & 72 & 5.6 & 104 & 5.1 & 101 & 5.1 & 277 & 5.3 \\
\hline Eisenhardt e Martin (2000) & 32 & 2.5 & 106 & 5.2 & 121 & 6.2 & 259 & 4.9 \\
\hline Dierickx e Cool (1989) & 71 & 5.6 & 91 & 4.5 & 96 & 4.9 & 258 & 4.9 \\
\hline Williamson (1975) & 79 & 6.2 & 104 & 5.1 & 73 & 3.7 & 256 & 4.9 \\
\hline Kogut e Zender (1992) & 54 & 4.2 & 83 & 4.1 & 90 & 4.6 & 227 & 4.3 \\
\hline Granovetter (1985) & 64 & 5.0 & 79 & 3.9 & 81 & 4.1 & 224 & 4.3 \\
\hline Peteraf (1993) & 53 & 4.2 & 90 & 4.4 & 79 & 4.0 & 222 & 4.2 \\
\hline Leonard-Barton (1992) & 42 & 3.3 & 74 & 3.7 & 80 & 4.1 & 196 & 3.7 \\
\hline Prahalad e Hamel (1990) & 63 & 4.9 & 74 & 3.7 & 57 & 2.9 & 194 & 3.7 \\
\hline Thompson (1967) & 72 & 5.6 & 71 & 3.5 & 49 & 2.5 & 192 & 3.6 \\
\hline Uzzi (1997) & 38 & 3.0 & 60 & 3.0 & 82 & 4.2 & 180 & 3.4 \\
\hline Amit e Schoemaker (1993) & 55 & 4.3 & 57 & 2.8 & 65 & 3.3 & 177 & 3.4 \\
\hline Jensen e Meckling (1976) & 48 & 3.8 & 67 & 3.3 & 62 & 3.2 & 177 & 3.4 \\
\hline Meyer e Rowan (1977) & 40 & 3.1 & 65 & 3.2 & 70 & 3.6 & 175 & 3.3 \\
\hline Burt (1992) & 47 & 3.7 & 62 & 3.1 & 65 & 3.3 & 174 & 3.3 \\
\hline Day e Wensley (1988) & 52 & 4.1 & 62 & 3.1 & 60 & 3.1 & 174 & 3.3 \\
\hline Henderson e Clarck (1990) & 46 & 3.6 & 66 & 3.3 & 61 & 3.1 & 173 & 3.3 \\
\hline Teece (1986) & 41 & 3.2 & 54 & 2.7 & 76 & 3.9 & 171 & 3.2 \\
\hline Levinthal e March (1993) & 38 & 3.0 & 64 & 3.2 & 68 & 3.5 & 170 & 3.2 \\
\hline Grant (1996) & 30 & 2.3 & 75 & 3.7 & 60 & 3.1 & 165 & 3.1 \\
\hline Barney (1986) & 50 & 3.9 & 52 & 2.6 & 62 & 3.2 & 164 & 3.1 \\
\hline Hurley e Hult (1998) & 45 & 3.5 & 48 & 2.4 & 66 & 3.4 & 159 & 3.0 \\
\hline Gatignon e Xuereb (1997) & 33 & 2.6 & 61 & 3.0 & 63 & 3.2 & 157 & 3.0 \\
\hline Tushman e Anderson (1986) & 42 & 3.3 & 58 & 2.9 & 56 & 2.8 & 156 & 3.0 \\
\hline Hakansson e Snehota (1995) & 31 & 2.4 & 55 & 2.7 & 66 & 3.4 & 152 & 2.9 \\
\hline Lieberman e Montgomery (1988) & 29 & 2.3 & 61 & 3.0 & 59 & 3.0 & 149 & 2.8 \\
\hline March e Simon (1958) & 40 & 3.1 & 60 & 3.0 & 44 & 2.2 & 144 & 2.7 \\
\hline Powell, Koput e Smith-Doerr (1996) & 38 & 3.0 & 56 & 2.8 & 54 & 2.7 & 148 & 2.8 \\
\hline Miles, Snow, Meyer e Coleman (1978) & 53 & 4.2 & 50 & 2.5 & 44 & 2.2 & 147 & 2.8 \\
\hline Hunt e Morgan (1995) & 51 & 4.0 & 50 & 2.5 & 42 & 2.1 & 143 & 2.7 \\
\hline North (1990) & 35 & 2.7 & 45 & 2.2 & 65 & 3.3 & 145 & 2.8 \\
\hline Levitt e March (1988) & 33 & 2.6 & 48 & 2.4 & 58 & 2.9 & 139 & 2.6 \\
\hline Williamson (1991) & 40 & 3.1 & 46 & 2.3 & 49 & 2.5 & 135 & 2.6 \\
\hline Huber (1991) & 41 & 3.2 & 56 & 2.8 & 31 & 1.6 & 128 & 2.4 \\
\hline Christensen e Bower (1996) & 34 & 2.7 & 52 & 2.6 & 38 & 1.9 & 124 & 2.4 \\
\hline
\end{tabular}

Notas: $1-n$ : $n^{o}$ de citações no período. 2 - \% da amostra em cada período.

Fonte: Elaborada pelos autores.

Nota-se que os trabalhos mais citados e, portanto, mais influentes, tiveram sua publicação concentrada nas décadas de 1980 e 1990, com poucos em períodos anteriores. Há trabalhos seminais que se mantêm influentes como Penrose (1959) sobre VBR e Cyert e March (1963) sobre decisões e aspectos comportamentais internos às empresas. Convém notar algumas flutuações importantes nas citações ao longo do tempo, são os valores sombreados. Assim, Porter
(1980, 1985) perdeu relevância no campo da formulação estratégica. Por outro lado, trabalhos sobre recursos e capacidades da empresa vêm crescendo em importância, indicando influência da VBR e seus desdobramentos (Teece, Pisano e Shuen, 1997; Eisenhardt e Martin, 2000; Cohen e Levinthal, 1990).

Tabela 3 apresenta os mais citados separados por origem da coleta (periódicos de marketing ou de estratégia). Importante notar que os trabalhos de 
Pesquisa em Marketing e Estratégia nos Principais Periódicos Internacionais: Um Estudo Bibliométrico sobre Publicações no Século XXI

estratégia que são mais utilizados em artigos de marketing, dizem respeito à utilização da VBR e de capacidades e recursos das empresas (Barney, 1991;
Teece, Pisano \& Shuen, 1997; Wernerfelt, 1984), da teoria dos custos de transação (Williamson, 1985) e organização industrial (Porter, 1980).

Tabela 3 - Trabalhos mais citados por período e por natureza do periódico coletado

\begin{tabular}{|c|c|c|c|c|c|c|c|c|}
\hline \multicolumn{3}{|c|}{$2001-2005$} & \multicolumn{3}{|c|}{$2006-2010$} & \multicolumn{3}{|c|}{2011 - 2014} \\
\hline & Mkg & Str & & Mkg & Str & & Mkg & Str \\
\hline Barney (1991) & 78 & 102 & Barney (1991) & 164 & 106 & Barney (1991) & 188 & 75 \\
\hline Porter (1980) & 79 & 66 & Day (1994) & 155 & 19 & $\begin{array}{c}\text { Teece, Pisano e Shuen } \\
\text { (1997) }\end{array}$ & 127 & 48 \\
\hline Day (1994) & 105 & 13 & $\begin{array}{c}\text { Teece, Pisano e Shuen } \\
(1997)\end{array}$ & 106 & 68 & $\begin{array}{c}\text { Cohen e Levinthal } \\
(1990)\end{array}$ & 92 & 53 \\
\hline Wernerfelt (1984) & 44 & 72 & Porter (1980) & 88 & 67 & Day (1994) & 139 & 3 \\
\hline $\begin{array}{l}\text { Pfeffer e Salancick } \\
\text { (1978) }\end{array}$ & 42 & 63 & Wernerfelt (1984) & 98 & 52 & Wernerfelt (1984) & 84 & 42 \\
\hline Williamson (1985) & 44 & 59 & $\begin{array}{c}\text { Cohen e Levinthal } \\
\text { (1990) }\end{array}$ & 75 & 74 & $\operatorname{March}(1991)$ & 74 & 49 \\
\hline Porter (1985) & 48 & 55 & Williamson (1985) & 79 & 57 & Porter (1980) & 78 & 43 \\
\hline $\begin{array}{c}\text { Nelson e Winter } \\
(1982)\end{array}$ & 27 & 71 & March (1991) & 61 & 71 & $\begin{array}{c}\text { Eisenhardt e Martin } \\
(2000)\end{array}$ & 88 & 33 \\
\hline $\begin{array}{c}\text { Teece, Pisano e Shuen } \\
\text { (1997) }\end{array}$ & 36 & 55 & Nelson e Winter (1982) & 42 & 80 & Dyer e Singh (1998) & 91 & 23 \\
\hline Penrose (1959) & 26 & 62 & Cyert e March (1963) & 44 & 73 & Penrose (1959) & 55 & 56 \\
\hline
\end{tabular}

Notas: 1 - Mkt: periódicos de marketing; Str: periódicos de estratégia. 2 - Valores correspondem ao $\mathrm{n}^{\mathrm{o}}$ de citações no período.

Fonte: Elaborada pelos autores.

\subsection{Análise de cocitações}

A análise de cocitação examina a frequência com que um par de referências é citado por outros autores. Com o auxílio do Ucinet, software voltado para análises de redes sociais, foi elaborada uma rede de cocitações com os 49 artigos mais citados em todo o período da pesquisa (Figura 3). Na rede de cocitações as linhas unem dois artigos que são citados simultaneamente e a espessura da linha indica a força da ligação entre eles, isto é, a frequência de cocitação. Deste modo, quanto mais espessa for a linha, maior a quantidade de vezes em que aquele par foi citado. $\mathrm{O}$ diâmetro do círculo é função do número de citações de cada artigo. 
Pesquisa em Marketing e Estratégia nos Principais Periódicos Internacionais: Um Estudo Bibliométrico sobre Publicações no Século XXI

Figura 3 - Rede de cocitações dos artigos mais citados - 2001 a 2014

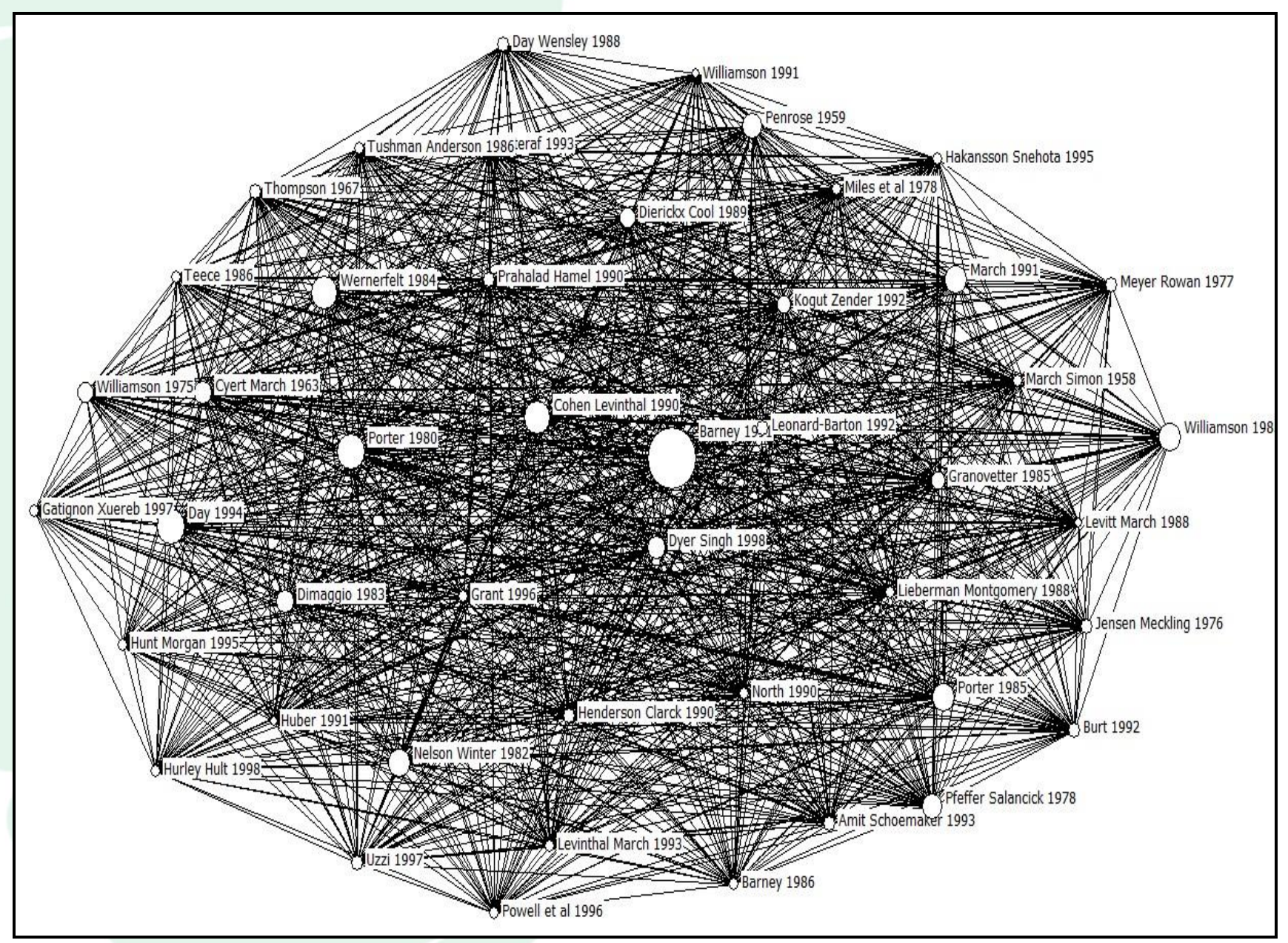

Fonte: Elaborado pelo autor utilizando software Ucinet for Windows

A leitura da rede de cocitações (Figura 3), que pode ser feita em conjunto ou por cada um dos pares de autores separadamente, permite obter uma compreensão geral da importância relativa dada a estes trabalhos. Importante notar que o software Ucinet dispõe os artigos de acordo com medidas de proximidade baseadas na frequência de cocitações e que a posição relativa é uma medida de centralidade relativa, pois nas posições mais centrais estão dispostos os trabalhos mais cocitados em termos absolutos. Por exemplo, o trabalho mais central é o de Barney (1991) e é mais cocitado com Wernerfelt (1984) e Penrose (1959).

Outros trabalhos, ainda que relevantes, como o de Cohen e Levinthal (1990) sobre capacidade absortiva ou os de Pfeffer e Salancick (1978) sobre dependência de recursos os de Williamson (1975 e 1985) sobre custos de transação têm posição menos central na rede relacional, denotando menor influência na elaboração dos artigos da amostra. Na periferia da Figura 3 estão trabalhos que, apesar de cocitados, são menos relevantes. Visto como um todo, estes são os trabalhos que melhor representam o tema abordado.

\subsection{Análise fatorial}

A análise fatorial pode ser usada para, a partir da matriz de cocitação, extrair subcampos ou conjuntos de artigos agrupados pelo conceito adotado (Lin \& Cheng, 2010), ou seja, reduzir a quantidade de variáveis, agrupando-as. A carga fatorial exprime o grau com que cada artigo pertence ao fator. $\mathrm{O}$ fator é o subcampo ou agrupamento de artigos em torno de um conceito comum (Nerur, Rasheed \& Natarajan, 2008). Os artigos que tratam de um mesmo tema tendem a ter altas cargas fatoriais num mesmo fator, portanto foram selecionados para o fator em que apresentam a maior carga. É conceitualmente possível que, apesar de um artigo estar num fator, ele também contribua com outras vertentes conceituais. Nesta pesquisa, a análise fatorial identificou três fatores, baseado na análise do diagrama de sedimentação (Hair et al., 1995), com $60,2 \%$ da variância explicada.

Tabela 4 apresenta um resumo da análise fatorial, com os componentes de cada fator e respectiva carga. Fator 1 foi nomeado de VBR/OI, fator 2 de 
Pesquisa em Marketing e Estratégia nos Principais Periódicos Internacionais: Um Estudo Bibliométrico sobre Publicações no Século XXI

KBV (knowledge-based view) e o fator 3 de TCT e

redes.

Tabela 4 - Resumo da análise fatorial

\begin{tabular}{|c|c|c|c|c|c|}
\hline \multicolumn{2}{|c|}{$\begin{array}{c}\text { Resource-based view e organização } \\
\text { industrial }\end{array}$} & \multicolumn{2}{|c|}{ Knowledge-based view } & \multicolumn{2}{|c|}{ Custos de transação e redes } \\
\hline Barney, 1991 & .511 & Cohen e Levinthal, 1990 & .676 & Williamson, 1985 & 649 \\
\hline Day, 1994 & .750 & Nelson e Winter, 1982 & .718 & Pfeffer e Salancick, 1978 & .660 \\
\hline Porter, 1980 & .733 & March, 1991 & .750 & Dyer e Singh, 1998 & .604 \\
\hline Wernerfelt, 1984 & .777 & Cyert e March, 1963 & .699 & Williamson, 1975 & .588 \\
\hline Porter, 1985 & .828 & Kogut e Zender, 1992 & .719 & Granovetter, 1985 & .738 \\
\hline Penrose, 1959 & .732 & Leonard-Barton, 1992 & .711 & Uzzi, 1997 & .699 \\
\hline Dierickx e Cool, 1989 & .741 & Thompson, 1967 & .514 & Jensen e Meckling, 1976 & .671 \\
\hline Peteraf, 1993 & .826 & $\begin{array}{l}\text { Henderson e Clarck, } \\
1990\end{array}$ & .818 & Meyer e Rowan, 1977 & .458 \\
\hline Prahalad e Hamel, 1990 & .872 & Teece, 1986 & .697 & Burt, 1992 & .749 \\
\hline Amit e Schoemaker, 1993 & .860 & Levinthal e March, 1993 & .828 & Hakansson e Snehota, 1995 & .650 \\
\hline Day, 1988 & .881 & $\begin{array}{l}\text { Tushman e Anderson, } \\
1986\end{array}$ & .799 & $\begin{array}{l}\text { Powell, Koput e Smith- } \\
\text { Doerr, } 1996\end{array}$ & .623 \\
\hline Hurley e Hult, 1998 & .729 & $\begin{array}{l}\text { Lieberman e } \\
\text { Montgomery, } 1988\end{array}$ & .555 & North, 1990 & .812 \\
\hline Gatignon e Xuereb, 1997 & .707 & March e Simon, 1958 & .663 & Williamson, 1991 & .644 \\
\hline $\begin{array}{l}\text { Miles, Snow, Meier e Coleman, } \\
1978\end{array}$ & .651 & Levitt e March, 1988 & .876 & & \\
\hline Hunt e Morgan, 1995 & .916 & Huber, 1991 & .676 & & \\
\hline & & Grant, 1996 & .594 & & \\
\hline Variância explicada (\%) & $36,8 \%$ & & $13,4 \%$ & & $10,0 \%$ \\
\hline
\end{tabular}

Notas: 1 - Valores correspondem à carga de cada fator. 2 - Total da variância explicada: 60,2\%

Fonte: Elaborada pelos autores.

O primeiro fator é composto por 15 trabalhos e pode ser dividido em dois grupos: um com 10 trabalhos sobre aplicações teóricas de VBR e outro com 5 artigos e livros sobre estratégia e organização industrial. O primeiro subfator é composto por artigos que discutem recursos e capacidades como ponto de partida para a estratégia organizacional (Barney, 1991; Day, 1994; Wernerfelt, 1984; Penrose, 1959; Dierickx e Cool, 1989; Peteraf, 1993). O segundo subfator apresenta trabalhos que abordam estratégias dirigidas para relações com o mercado e competidores (Porter, 1980; 1985; Day, 1988). Uma das possíveis explicações para as duas teorias fazerem parte de um mesmo fator pode ser a prática de marketing ser definida na fronteira da empresa com o mercado, a dependência dos concorrentes na medida em que os resultados de atividades de marketing passam sempre pelos consumidores.

O segundo fator, composto por 16 trabalhos voltados à aquisição de conhecimento como diferencial para obtenção de desempenho (Cohen \& Levinthal, 1990; Grant, 1996; Kogut \& Zander, 1992; Leonard-
Barton, 1992; Levinthal \& March, 1993; March, 1991). Importante notar que este fator traz alguns artigos relacionados a inovações, como uma forma da empresa transformar conhecimento em geração de renda (Henderson \& Clark, 1990; Lieberman \& Montgomery, 1988; Teece, 1986).

O terceiro fator é formado por 13 artigos que abordam a teoria dos custos de transação e aspectos da formação de redes organizacionais, tópico também relacionado a custos de transação. Assim, aspectos dos custos de transação são tratados de várias maneiras. Dyer e Singh (1998); Williamson (1975, 1985, 1991) tratam de alianças entre empresas ou com poder público; Pfeffer e Salancick (1978) discutem o controle externo das empresas por meio da dependência de recursos e vantagens na formação de alianças para ter acesso a recursos; Hakansson e Snehota (1995); Powell, Koput, e Smith-Doerr (1996) e Uzzi (1997) discutem formação de redes entre organizações e Burt (1995) e Granovetter (1985) tratam de aspectos sociais, o primeiro dos buracos estruturais à espera de um agente externo para preenchê-los e gerar desempenho e 
Pesquisa em Marketing e Estratégia nos Principais Periódicos Internacionais: Um Estudo Bibliométrico sobre Publicações no Século XXI

o segundo trata da estrutura social da empresa e relações institucionais.

$\begin{array}{cccccc}\text { proximidades } & \begin{array}{c}\text { Figura } \\ \text { gerado }\end{array} & \begin{array}{c}\text { traz } \\ \text { pelo }\end{array} & \text { o } & \begin{array}{c}\text { diagrama de } \\ \text { escalonamento }\end{array}\end{array}$ multidimensional de proximidades (MDS proxscal) confirmando o agrupamento obtido pela análise fatorial nos três fatores (Tabela 6).

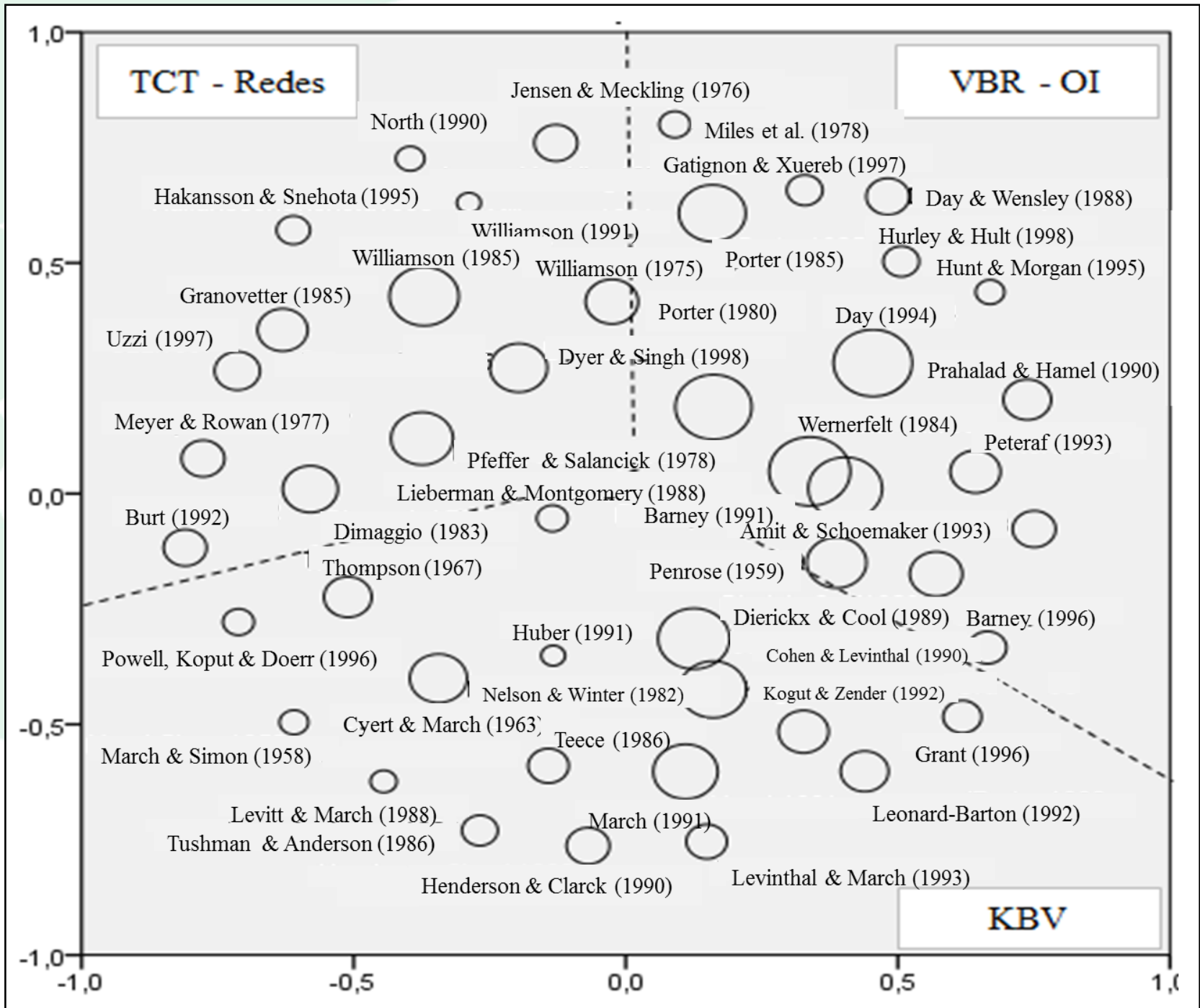

Figura 4 - Diagrama MD

Fonte: Elaborado pelo autor utilizando software SPSS.

\subsection{Análise Temporal}

Para análise da evolução temporal, o período amostral foi dividido em três subperíodos de cinco anos (o último com quatro anos, 2011 a 2014). É importante notar que a utilização de conceitos de VBR vem se mantendo em todo o período, chegando a ter, no artigo de Barney (1991) o mais citado em cada período e no total dos 14 anos da pesquisa, além deste, estão presentes entre as referências mais citadas. Barney (1986), Penrose (1959) e Peteraf (1993) entre outros. Em associação com VBR, as abordagens sobre capacidades das empresas, evolução e adaptação destas capacidades ao longo do tempo, mediante estímulos do ambiente (Eisenhardt \& Martin, 2000; Grant, 1996; Prahalad \& Hamel, 1990), bem como abordagens de aprendizagem organizacional e KBV (Cohen \& Levinthal, 1990; Henderson \& Clark, 1990; Kogut \& Zander, 1992; Leonard-Barton, 1992; Levinthal \& March, 1993), também são frequentemente empregadas, sempre voltadas à obtenção de bom desempenho e relacionadas às estratégias de marketing. 
Pesquisa em Marketing e Estratégia nos Principais Periódicos Internacionais: Um Estudo Bibliométrico sobre Publicações no Século XXI

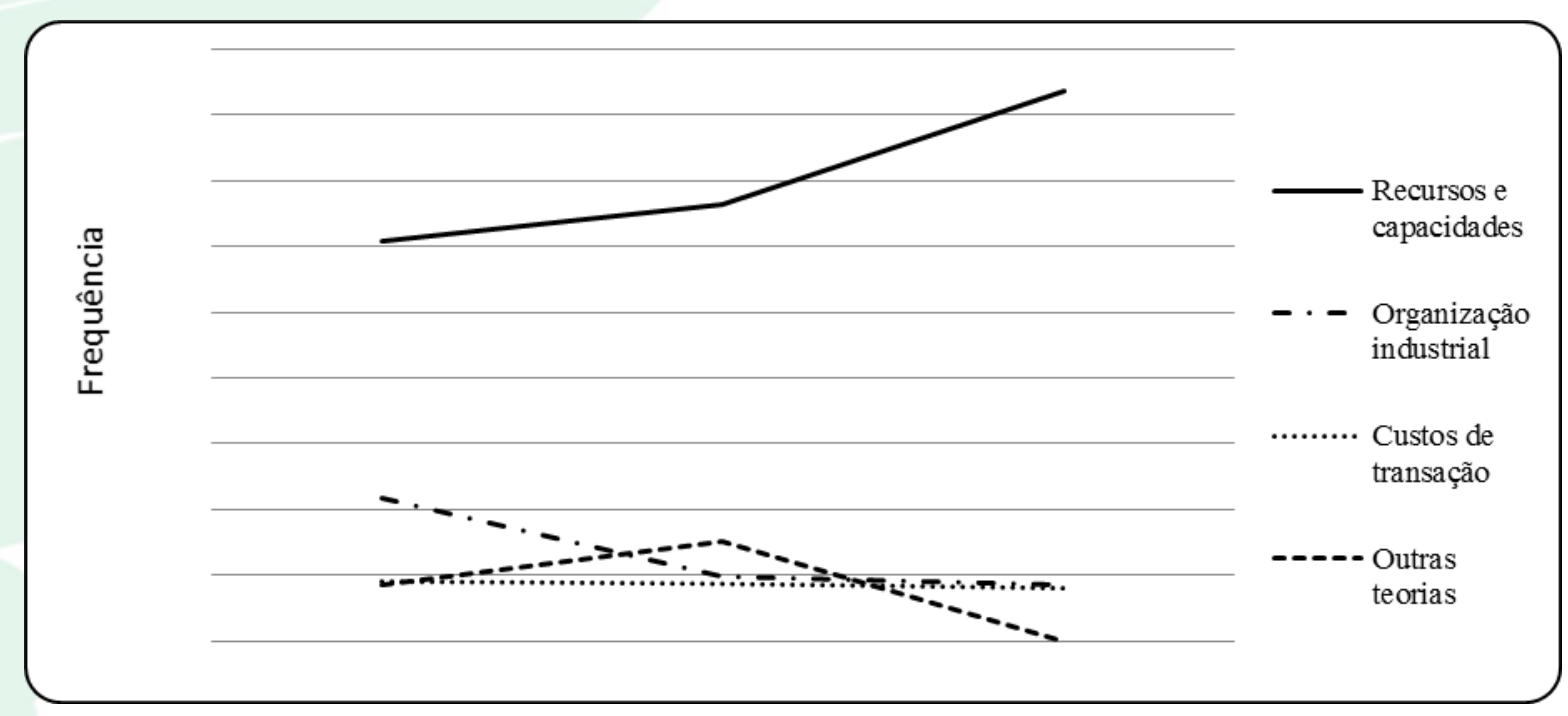

Figura 5 - Frequência relativa de citação por tópico

Fonte: Elaborada pelos autores.

Trabalhos sobre custos de transação, formação de redes e alianças e organização industrial e vêm decrescendo em frequência de citação. A análise da Figura 5, com a frequência relativa de citação para os trabalhos mais citados por período, permite a constatação da dominância de trabalhos relacionados a VBR e do decréscimo de abordagens voltadas à teoria dos custos de transação e da visão da estratégia competitiva industrial, caracterizada nos trabalhos de Porter $(1980,1985)$. Mesmo que a prática de marketing seja o mediador entre os recursos estratégicos e os resultados dependentes dos consumidores (ex: desejo para pagar mais, valor agregado aos produtos e serviços, Market share, lealdade e lucratividade dos clientes).

\section{CONSIDERAÇÕES FINAIS, LIMITAÇÕES E SUGESTÕES PARA PESQUISAS FUTURAS}

Uma pesquisa bibliométrica ajuda a organizar o conhecimento acumulado de determinado tópico de estudo. Neste estudo foi conduzida uma pesquisa para verificar o entrelaçamento existente entre duas áreas da administração: marketing e estratégia. Para tal, foram coletados nos vinte melhores ranqueados periódicos de marketing, artigos que utilizaram teorias ou aplicações de estratégia e nos vinte mais bem classificados periódicos de estratégia, trabalhos com viés de marketing, estabelecendo, deste modo, o diálogo entre as duas áreas. Foram obtidos 5270 artigos publicados a partir de 2001. O método de pesquisa empregado foi a bibliometria, baseado em técnicas de citação e cocitação, além disso, foi conduzida uma análise fatorial e uma análise multidimensional com caráter confirmatório para a fatorial.
Os objetivos desta pesquisa foram: identificar as abordagens mais utilizadas que compõem o estoque de artigos da amostra de vinte relevantes periódicos das áreas de estratégia e marketing; apontar evidências empíricas da relação entre marketing e estratégia por meio de trabalhos que abordem concomitantemente as duas áreas de conhecimento e apontar os trabalhos mais influentes na intersecção entre estas duas áreas. Estes objetivos foram considerados alcançados, pois os resultados obtidos: apontaram que a VBR, TCT e organização industrial (OI) são os temas oriundos de estudos de estratégia mais empregados em artigos associados a marketing, conforme descrito na Seção Análise Fatorial e detalhado na Tabela 4; ao identificar um número alto de artigos relacionando as duas áreas de conhecimento à mesma abordagem, fornecem uma evidencia empírica de que estratégia e marketing estão relacionados, principalmente nestas três abordagens, quais sejam: VBR, TCT e OI, o que confirma os trabalhos de Ramos-Rodríguez \& Ruíz-Navarro (2004) e Shafique (2013) sobre a influência crescente das abordagens envolvendo a visão baseada em negócios e capacidades nos estudos envolvendo estratégia e, em particular, marketing e estratégia (Kozlenkova et al.,2014) e identificaram Barney (1991), Day (1994) e Teece, Pisano e Shuen (1997) como os trabalhos mais referenciados em todo o período, além do ranking contendo outros trabalhos, de acordo com as Tabelas 2 e 3 .

Este estudo apresenta limitações que são inerentes ao método bibliométrico. A primeira refere-se à necessidade de escolha das palavras-chave utilizadas na obtenção da amostra que, apesar de haverem capturado parte significativa da publicação sobre os temas deste artigo, não 
consideraram todos os artigos que relacionam marketing e estratégia. A segunda limitação da bibliometria está associada aos periódicos pesquisados que não cobrem toda a pesquisa publicada, ainda que tenham sido eleitos os 20 principais periódicos (10 especializados em marketing e 10 em estratégia), mas que trazem o que de mais importante foi produzido. Desta maneira, futuros trabalhos podem ampliar a seleção dos periódicos e incluir aqueles especializados em outras áreas como finanças, vendas ou recursos humanos, além de utilizar outras palavras-chave.

Outra limitação inerente à pesquisa bibliométrica é a temporalidade, uma vez que artigos clássicos escritos a mais tempo, têm maior possibilidade de ser citados, mesmo como um trabalho seminal. Um artigo igualmente relevante para o tema pesquisado poderia ser relativamente classificado como menos importante, pois não houve tempo para que ele fosse citado pela mesma quantidade de trabalhos. Esta limitação foi parcialmente contornada com a divisão do período pesquisado em três períodos menores. De qualquer maneira, esta limitação indica que futuros trabalhos devem ser realizados para verificar se não houve alteração nas referências durante o decorrer do tempo.

Nesta pesquisa foi utilizada uma análise de citações que se restringiu à contagem das vezes em que determinado artigo foi citado, independente do contexto em que o foi. Futuras pesquisas podem realizar uma análise de conteúdo, com a finalidade de identificar os vários contextos em que uma mesma referência é citada e introduzindo uma nova dimensão à análise de citações. Pesquisas futuras podem investigar aspectos mais específicos da teoria tanto de marketing quanto de estratégia, os laços que conectam estas duas áreas do conhecimento, neste caso podem ser investigados autores e o conteúdo dos artigos que transitam pelas duas áreas, publicando em periódicos de estratégia e de marketing.

Williamson e Ghani (2012) apontam que pesquisas futuras em marketing usando TCT devem ter como os principais tópicos a serem abordados a assimetria de custos, as dinâmicas de governança, aspectos de desequilíbrios contratuais, aspectos sociológicos como confiança, e comportamento oportunista. Os autores sustentam também que, em termos de metodologia, acadêmicos que trazem TCT para questões de marketing têm predominância pelo uso de aplicações práticas, reconhecem a importância da microanálise dos aspectos envolvidos, entendem que a TCT é importante e acreditam na necessidade de uma análise multifacetada para englobar toda a complexidade da teoria. Essas preocupações não são exclusividade da área de marketing, e também devem ser consideradas nos estudos que tem como ênfase questões da área de estratégia.

Os resultados deste estudo bibliométrico estão alinhados com outras pesquisas bibliométricas e ensaios teóricos recentemente publicados que apresentaram questões de pesquisa relacionando VBR,
TCT e outras teorias que inicialmente surgiram em estratégia (Angulo-Ruiz, Donthu, Prior, \& Rialp, 2014; Kozlenkova, Samaha \& Palmatier, 2014; Wernerfelt, 2014). Dessa forma sugestões de pesquisa aplicadas com base na relação entre VBR, TCT, Teoria da dependência de recursos e Redes de relacionamento cabem como inspiração de estudos futuros na fronteira entre estratégia e marketing. Podem ser listadas as seguintes sugestões de pesquisas futuras:

1. Como podem diferentes perspectivas teóricas gerar insghts para contingências da VBR. Por que algumas empresas têm sucesso em mercados emergentes ou criam novas oportunidades de mercado em condições econômicas de baixa demanda?

2. Como várias teorias de estratégia podem ser mais bem integradas para otimizar tomada de decisão sobre recursos de marketing ou desenvolvimento de capacidades de marketing.

3. Em quanto investimentos específicos de transação são mais prováveis para gerar retornos econômicos sobre a VBR, na perspectiva da TCE, investimentos específicos tornam a firma vulnerável ao comportamento oportunista. $\mathrm{O}$ comportamento oportunista, em marketing, poderia ser tratado por meio do consumidor e canais de distribuição como agentes envolvidos nas transações ou relacionamentos com agentes principais (Ex: marcas). Não é claro como seria melhor integrar esses potenciais efeitos positivos e negativos para identificar a melhor estratégia para as empresas.

4. Outra questão que relaciona VBR e ECT trata do efeito de mecanismos de governança. Enquanto mecanismos de governança podem ajudar a alinhar o comportamento de agentes na relação com o agente principal (ex: componentes da cadeia de distribuição ou consumidores finais com uma grande empresa produtora de multimarcas) e mitigar oportunismo. Os mesmos mecanismos de governança, na perspectiva da VBR, podem interferir na utilização ótima de recursos. Por exemplo, se a autonomia de governança é restringida, os sinais não são confiáveis e as normas relacionais são minadas, não é claro se a empresa teria benefício. A TCE sugere que essas estratégias minimizam custos de transação, mas a VBR indica que as estratégias inibem a exploração de recursos.

5. Como a complexidade das redes de relacionamento pode ser analisada no contexto da VBR. Quais características das redes de relacionamento capacitam recursos de rede que reúnam os requisitos do VRIO.

6. Em quais contextos de mercado, valor da marca, reputação, satisfação do consumidor reúnem os requisitos do VRIO e influenciam os resultados econômicos da empresa. 
Observou-se que estas áreas do conhecimento, quais sejam marketing e estratégia, são substancialmente relacionadas e acredita-se que o intercâmbio de proposições teóricas e evidências empíricas podem acelerar a ciência para ambas por meio da investigação das questões propostas e outras mais que surjam a medida que estudos na fronteira dessas duas áreas.

\section{REFERÊNCIAS}

Acedo, F. J., Barroso, C., \& Galan, J. L. (2006). The resource-based theory: dissemination and main trends. Strategic Management Journal, 27(7), 621636. doi:10.1002/smj.532

Angulo-Ruiz, F., Donthu, N., Prior, D., \& Rialp, J. (2014). The financial contribution of customeroriented marketing capability. Journal of the Academy of Marketing Science, 42(4), 380-399. doi:10.1007/s11747-013-0353-6

Barney, J. (1986). Strategic factor markets: expectations, luck and business strategy. Management Science, 32(10), 1231-1241.

Barney, J. (1991). Firm Resources and Sustained Competitive Advantage. Journal of Management, 17(1), 99-120.

Barney, J. (2013). How marketing scholars might help address issues in resource-based theory. Journal of the Academy of Marketing Science, 42(1), 24-26. doi:10.1007/s11747-013-0351-8

Barney, J., \& Hesterly, W. (2009). Strategic Management and Competitive Advantage: Concepts and Cases, 656.

Barney, J., Ketchen, D. J., \& Wright, M. (2011). The Future of Resource-Based Theory: Revitalization or Decline? Journal of Management, 37(5), 12991315. doi:10.1177/0149206310391805

Bazeley, P. (2013). Qualitative Data Analysis. London: Sage Publications Ltd.

Bernard, H., \& Ryan, G. (2010). Analyzing Qualitative Data: Systematic Approaches (Vol. 15). Los Angeles, CA: Sage Publications Inc.

Borgatti, S. P., Everett, M. G., \& Freeman, L. C. (2002). Ucinet for Windows: Software for Social Network Analysis. Harvard, MA: Analytic Technologies.

Broadus, R. N. (1987). Toward a definition of “bibliometrics." Scientometrics, 12(5-6), 373-379.
Brown, J. R., \& Dant, R. P. (2008). Scientific method and retailing research: A retrospective. Journal of Retailing, $\quad 84(1), \quad 1-13$. doi:10.1016/j.jretai.2008.03.001

Brown, J. R., \& Dant, R. P. (2009). The Theoretical Domains of Retailing Research: A Retrospective. Journal of Retailing, 85(2), 113-128. doi:10.1016/j.jretai.2009.04.003

Burt, R. S. (1995). Structural Holes: The Social Structure of Competition. Cambridge, MA: Harvard University Press.

Chabowski, B. R., Samiee, S., \& Hult, G. T. M. (2013). A bibliometric analysis of the global branding literature and a research agenda. Journal of International Business Studies, 44(6), 622-634. doi:10.1057/jibs.2013.20

Cohen, W. M., \& Levinthal, D. A. (1990). Absorptive capacity: a new perspective on learning and innovation. Administrative Science Quarterly, 35, 118-152. Retrieved from http://www.jstor.org/stable/2393553

Cyert, R., \& March, J. G. (1963). A Behavioral Theory of the Firm. Englewood Cliffs, NJ: Prentice-Hall.

Day, G. S. (1994). The capabilities of market-driven organizations. Journal of Marketing, 58(October), 37-52. doi:10.2307/1251915

Deshpande, R., Farley, J. U., \& Webster, Frederick E., J. (1993). Corporate culture, customer orientation , and innovativeness in japanese firms: A quadrad analysis. Journal of Marketing, 57(January), 23-27. doi: $10.2307 / 1252055$

Dickson, P. R., Farris, P. W., \& Verbeke, W. J. (2001). Dynamic strategic thinking. Journal of the Academy of Marketing Science, 29(3), 216-237.

Dierickx, I., \& Cool, K. (1989). Asset stock accumulation and sustainability of competitive advantage. Management Science, 35(12), 15041512.

Diodato, V. (1994). Dictionary of Bibliometrics. Binghamton, N.Y.: Haworth Press.

Dwyer, F. R., Schurr, P. H., \& Oh, S. (1987). Developing buyer-seller relationships. Journal of Marketing, 51(April), 11-27. doi:10.2307/1251126

Dyer, J. H., \& Singh, H. (1998). The relational view: Cooperative strategy and sources of interorganizational competitive advantage. Academy of Management Review, 23(4), 660-679. doi:10.7880/abas.13.77 
Eisenhardt, K. M., \& Martin, J. A. (2000). Dynamic capabilities: what are they? Strategic Management Journal, 21(10-11), 1105-1121. doi:10.1002/10970266(200010/11)21:10/11<1105::AIDSMJ133>3.0.CO;2-E

Fabrigar, L. R., Wegener, D., \& MacCallun, R. (1999). Evaluating the use of exploratory factor analysis in psychological research. Psychological Methods, 4(3), 272-299.

Frels, J., Shervani, T., \& Srivastava, R. (2003). The Integrated Networks Model: Explaining Resource Allocations in Network Markets. Journal of Marketing, 67(January), 29-45. doi:10.1509/jmkg.67.1.29.18586

Ghosh, M., \& John, G. (1999). Governance value analysis and marketing strategy. Journal of Marketing, 63, 131-145. Retrieved from http://search.proquest.com/docview/227817565?acc ountid=10297\nhttp://sfx.cranfield.ac.uk/cranfield? url_ver=Z39.88-

2004\&rft_val_fmt=info:ofi/fmt:kev:mtx:journal\&g enre=article \&sid=ProQ:ProQ:abiglobal\&atitle $=$ Gov ernance+value+analysis+and+marketing+strategy \& $\mathrm{t}$

Granovetter, M. (1985). Economic action and social structure: The problem of embeddedness. American Journal of Sociology, 91(3), 481-510.

Grant, R. M. (1996). Toward a knowledge-based theory of the firm. Strategic Management Journal, 17(Winter), 109-122. doi:10.2307/2486994

Guedes, V. S., \& Borschiver, S. (2005). Bibliometria: uma ferramenta estatística para a gestão da informaçao e do conhecimento em sistemas de informaçao, de comunicaçao e de avaliaçao científica e tecnológica. In ICI/UFBA (pp. 1-18).

Hair, J. F., Tatham, R. L., \& Black, W. (1995). Multivariate Data Analysis. New York: PrenticeHall.

Hakansson, H., \& Snehota, I. (1995). Developing Relationships Business Networks. London: Routledge. Londres: Routledge.

Helfat, C., \& Peteraf, M. (2009). Understanding dynamic capabilities: progress along a developmental path. Strategic Organization, 7(1), 91-102. doi:10.1177/1476127008100133

Henderson, R. M., \& Clark, K. B. (1990). Architectural innovation: The reconfiguration of existing product technologies and the failure of established firms.
Administrative Science Quarterly, 35, 9-30. doi:Article

Hoffman, D. L., \& Holbrook, M. B. (1993). The intellectual structure of consumer research: A bibliometric study of author cocitations in the first 15 years of the Journal of Consumer Research. Journal of Consumer Research, 19(March), 505517. doi:10.1086/209319

Jaakkola, M., Moller, K., Parvinen, P., Evanschitzky, Hh., \& Muhlbacher, H. (2010). Strategic marketing and business performance: A study in three European "engineering countries." Industrial Marketing Management, 39(8), 1300-1310. Retrieved from http://www.scopus.com/inward/record.url?eid=2s2.0$78649322403 \&$ partnerID $=40 \& \mathrm{md} 5=61 \mathrm{f} 5 \mathrm{c} 02 \mathrm{c} 7 \mathrm{c} 8 \mathrm{a}$ $730 \mathrm{ad} 87 \mathrm{ad} 62483 \mathrm{c} 9 \mathrm{cccb}$

Jaworski, B. J., \& Kohli, A. K. (1993). Market orientation: Antecedents and consequences. Journal of Marketing, 57(July), 53-70.

John, G., \& Reve, T. (2010). Transaction cost analysis in marketing: looking back, moving forward. Journal of Retailing, 86(3), 248-256. doi:10.1016/j.jretai.2010.07.012

Johnson, J. L., Sohi, R. S., \& Grewal, R. (2004). The Role of Relational Knowledge Stores in Interfirm Partnering. Journal of Marketing, 68(July), 21-36. doi:10.1509/jmkg.68.3.21.34765

Kogut, B., \& Zander, U. (1992). Knowledge of the firm, combinative capabilities, and the replication of technology. Organization Science, 3(3), 383397. doi:10.1287/orsc.3.3.383

Kogut, B., \& Zander, U. (1996). What firms do? Coordination, identity, and learning. Organization Science, 7(5), 502-518.

Kohli, A. K., \& Jaworski, B. J. (1990). Market orientation: The construct, research propositions, and managerial implications. Journal of Marketing, 54(April), 1-18.

Kozlenkova, I. V., Samaha, S. A., \& Palmatier, R. W. (2014). Resource-based theory in marketing. Journal of the Academy of Marketing Science, 42, 1-21. doi:10.1007/s11747-013-0336-7

Krasnikov, A., \& Jayachandran, S. (2008). The Relative impact of marketing, research-anddevelopment, and operations capabilities on firm performance. Journal of Marketing, 72(4), 1-11. doi:10.1509/jmkg.72.4.1 
Kumar, V. (2015). Evolution of Marketing as a Discipline : What Has Happened and What to Look Out For. Journal of Marketing, 79, 1-9.

Leonard-Barton, D. (1992). Core capabilities and core rigidities: A paradox in managing new product development. Strategic Management Journal, 13(S1), 111-125. doi:10.1002/smj.4250131009

Levinthal, D. A., \& March, J. G. (1993). The myopia of learning. Strategic Management Journal, 14, 95112. doi:10.1002/smj.4250141009

Lieberman, M. B., \& Montgomery, D. B. (1988). Firstmover advantages. Strategic Management Journal, 9, 41-58. doi:10.2307/2486211

Lin, T. Y., \& Cheng, Y. Y. (2010). Exploring the knowledge network of strategic alliance research: A co-citation analysis. International Journal of Electronic Business Management, 8(2), 152-160. Retrieved from http://140.114.53.122/IJEBM_Web/IJEBM_static/P aper-V8_N2/A07.pdf

Lippman, S. A., \& Rumelt, R. P. (1982). Uncertain imitability: an analysis of interfirm differences in efficiency under competition. The Bell Journal of Economics, 13(2), 418-438.

March, J. G. (1991). Exploration and exploitation. Organization Science, 2(1), 71-87.

McCain, K. W. (1986). Cocited author mapping as a valid representation of intellectual structure. Journal of the American Society for Information Science, 37(3), 111-122. doi:10.1002/asi.4630370303

Morgan, N. A., Vorhies, D. W., \& Mason, C. H. (2009). Market orientation, marketing capabilities, and firm performance. Strategic Management Journal, 30(8), 909-920. doi:10.1002/smj

Morgan, R. M., \& Hunt, S. D. (1994). The Commitment-Trust Theory of Relationship Marketing. Journal of Marketing, 58(3), 20-38. doi: $10.2307 / 1252308$

Narver, J. C., \& Slater, S. F. (1990). The effect of a market orientation on business profitabitity. Journal of Marketing, (October), 20-35. doi:10.2307/1251757

Nerur, S. P., Rasheed, A. A., \& Natarajan, V. (2008). The intellectual structure of the strategic management field: An author co-citation analysis. Strategic Management Journal, 29, 319-336. doi:10.1002/smj
Palacios-Huerta, I., \& Volij, O. (2003). The measurement of intellectual influence. Brown University, Economics Working .... Retrieved from http://papers.ssrn.com/sol3/papers.cfm?abstract_id= 329803

Penrose, E. (1959). The Theory of the Growth of the Firm. Oxford: Oxford University Press.

Peteraf, M. A. (1993). The cornerstones of competitive advantage: a resource-based view. Strategic Management Joumal, 14(3), 179-191.

Pfeffer, J., \& Salancick, G. R. (1978). The External Control of Organizations: A Resource Dependence Perspective. New York: Harper \& Row.

Pilkington, A. (2006). Bibexcel - Quick Start Guide to Bibliometrics and Citation Analysis.

Pilkington, A., \& Meredith, J. (2009). The evolution of the intellectual structure of operations management-1980-2006: A citation/co-citation analysis. Journal of Operations Management, 27(3), 185-202. doi:10.1016/j.jom.2008.08.001

Podsakoff, P. M., MacKenzie, S. B., Lee, J.-Y., \& Podsakoff, N. P. (2003). Common method biases in behavioral research: a critical review of the literature and recommended remedies. The Journal of Applied Psychology, 88(5), 879-903. doi:10.1037/0021-9010.88.5.879

Porter, M. (1980a). Competitive Strategy. New York: Free Press - Simon \& Schuster Inc.

Porter, M. (1980b). Competitive Strategy Chap.1. New York: Free Press.

Porter, M. (1985). Competitive Advantage. New York: Free Press.

Powell, W. W., Koput, K. W., \& Smith-Doerr, L. (1996). Interorganizational collaboration and the locus of collaboration: networks of learning in biotechnology. Administrative Science Quarterly, $41,116-145$.

Prahalad, C. K., \& Hamel, G. (1990). The Core Competence of the Corporation. Harvard Business Review, maio-junho.

Ramos-Rodríguez, A.-R., \& Ruíz-Navarro, J. (2004). Changes in the intellectual structure of strategic management research: a bibliometric study of theStrategic Management Journal, 1980-2000. Strategic Management Journal, 25(10), 981-1004. doi:10.1002/smj.397 
Richman, B., \& Macher, J. (2008). Transaction cost economics: An assessment of empirical research in the social sciences. Business and Politics, 10, 1-63. doi:10.2202/1469-3569.1210

Serra, F. A. R., Ferreira, M. P., \& Almeida, M. I. R. De. (2012). A pesquisa em administraçao estratégica nos primeiros anos do século XXI: um estudo bibliométrico de citaçao e cocitaçao no Strategic Management Journal entre 2001 e 2007. R. Eletr. Estrat. Neg. Florianópolis, 5(2), 257-274.

Serra, F. A. R., Ferreira, M. P., \& Almeida, M. I. R. De. (2013). Organizational decline: a yet largely neglected topic in organizational studies. Management Research: The Journal of the Iberoamerican Academy of Management, 11(2), 133-156. doi:10.1108/MRJIAM-Mar-2012-0476

Shafique, M. (2013). Thinking inside the box? Intellectual structure of the knowledge base of innovation research (1988-2008). Strategic Management Journal, 34, 62-93. doi:10.1002/smj

Sheng, S., Zhou, K. Z., \& Li, J. J. (2011). The effects of business and political ties on firm performance: evidence from China. Journal of Marketing, 75(January), 1-15. doi:10.1509/jmkg.75.1.1

Simonin, B. L. (1999). Transfer of Marketing KnowHow in International Strategic Alliances: An Empirical Investigation of the Role and Antecedents of Knowledge Ambiguity. Journal of International Business Studies, 30, 463-490. doi:10.1057/palgrave.jibs.8490079

Slater, S. F., \& Narver, J. C. (1995). Market orientation and the learning organization. Journal of Marketing, 59(July), 63-74. doi:10.2307/1252120

Srivastava, R. K., Shervani, T. a, \& Fahey, L. (1999). Marketing, Business Processes and Shareholder Value: An Organizationaiiy Embedded View of Marlceting Activities and the Discipline of iViarketing. Journal of Marketing, 63, 168-179. doi:10.2307/1252110

Srivastava, R. K., Shervani, T. A., \& Fahey, L. (1998). Market-based assets and shareholder value: A framework for analysis. Journal of Marketing, 62(January), 2-18. doi:10.2307/1251799

Steenkamp, J. B. E. M., \& Geyskens, I. (2012). Transaction cost economics and the roles of national culture: A test of hypotheses based on Inglehart and Hofstede. Journal of the Academy of Marketing Science, 40, 252-270. doi:10.1007/s11747-011-0266-1
Teece, D. (1986). Profiting from technological innovation: Implications for integration, collaboration, licensing and public policy. Research Policy, 15(February), 285-305. Retrieved from http://www.sciencedirect.com/science/article/pii/00 48733386900272

Teece, D. (2007). Explicating dynamic capabilities: the nature and microfoundations of (sustainable) enterprise performance. Strategic Management Journal, 28, 1319-1350. doi:10.1002/smj

Teece, D. (2010). Forward integration and innovation: transaction costs and beyond. Journal of Retailing, 86(3), 277-283. doi:10.1016/j.jretai.2010.07.013

Teece, D., Pisano, G., \& Shuen, A. (1997). Dynamic capabilities and strategic management. Strategic Management Joumal, 18(March), 509-533. Retrieved from http://books.google.com/books?hl=en \&lr=\&id=hDz MIC8mij4C\&oi=fnd\&pg=PA234\&dq=DYNAMIC +CAPABILITIES+AND+STRATEGIC+MANAG EMENT\&ots=zIg-

AnmKAO\&sig=oBsv2uH9fhj9iqKM2pEcw83gHC 0

Theodosiou, M., Kehagias, J., \& Katsikea, E. (2012). Strategic orientations, marketing capabilities and firm performance: An empirical investigation in the context of frontline managers in service organizations. Industrial Marketing Management, 41(7), 1058-1070. doi:10.1016/j.indmarman.2012.01.001

Uzzi, B. (1997). Social structure and competition in interfirm networks: The paradox of embeddedness. Administrative Science Quarterly, 42, 35-67. doi:10.2307/2393808

Varadarajan, P. R., \& Jayachandran, S. (1999). Marketing Strategy: an assessment of the state of the field and outlook. Journal of the Academy of Marketing Science, 27(2), 120-143. Retrieved from http://scholar.google.com/scholar?hl=en\&btnG=Sea rch\&q=intitle:Copyright+?+1998.+All+rights+reser ved.\#0

Wernerfelt, B. (1984). A resource-based view of the firm. Strategic Management Joumal, 5(2), 171180.

Wernerfelt, B. (2014). On the role of the RBV in marketing. Journal of the Academy of Marketing Science, 42, 22-23. doi:10.1007/s11747-013-03358

Williamson, O. E. (1975). Markets and Hierarchies: Analysis and Antitrust Implications. New York: Free Press. 
Pesquisa em Marketing e Estratégia nos Principais Periódicos Internacionais: Um Estudo Bibliométrico sobre Publicações no Século XXI

Williamson, O. E. (1985). The Economic Institutions of Capitalism. New York: Free Press.

Williamson, O. E. (2010). Transaction cost economics: The natural progression. Journal of Retailing, 86(3), 215-226. doi:10.1016/j.jretai.2010.07.005

Williamson, O. E., \& Ghani, T. (2012). Transaction cost economics and its uses in marketing. Journal of the Academy of Marketing Science, 40(July 2011), 74-85. doi:10.1007/s11747-011-0268-Z
Wu, J. (2013). Marketing capabilities, institutional development, and the performance of emerging market firms: A multinational study. International Journal of Research in Marketing, 30(1), 36-45. doi:10.1016/j.ijresmar.2012.07.001

Zander, U., \& Kogut, B. (1995). Knowledge and the speed of the transfer and imitation of organizational capabilities: an empirical test. Organization Science, 6(6), 76-92. 